\title{
Short Term Power load Forecasting Considering Meteorological Factors
}

\author{
Jing Luo ${ }^{1,}$ a \\ ${ }^{1}$ Department of economics and management, North China Electric Power University, Baoding, \\ Hebei, China \\ aj521013@qq.com
}

\begin{abstract}
To forecast short-term power load, we first establish GM $(1,1)$ grey forecasting model and test the correlation of the predicted values. Considering the impact of meteorological factors on modern power system, we establish a load forecasting model based on principal component analysis and multiple linear regression analysis. Then we compare the two kinds of load forecasting model by the precision of curve fitting with the actual load. The results show that the accurate of short-term load forecasting model included in meteorological factors is higher, we also introduce an assessment standard to provide evidence.
\end{abstract}

Keywords: Short-term power load forecasting, Meteorological factors, Principal component regression analysis.

\section{Introduction}

Short term load forecasting is an important means to ensure the scientific decision of power system optimization. Xiaojuan Liu established for middle power load forecasting of partial least squares regression analysis model and analysis the prediction accuracy and practicability of the model. Lijun Sun established a combined forecasting model of power load forecasting and based on multiple linear regression, and the forecast results of the model are analyzed and compared with the results predicted by the grey prediction model alone. Peng Peng, Jiahong Peng proposed a short-term power load forecasting method based on BP neural network, combined with temperature and humidity, established a regression model for forecasting the power load considering real-time meteorological factors. Yahong Chen, Li Ma proposed a new short-term load forecasting accuracy assessment standard, and defined the application scope and feasibility of this assessment standard.

The research about short-term power load forecasting method considering meteorological factors is still lacking, such as the selection of meteorological factors is not reasonable. For this, we establish a power load forecasting model considering meteorological factors (daily maximum temperature, daily average temperature, daily average humidity, daily rainfall forecast) based on a principal component analysis and multiple linear regression. The analysis results show that the short-term load forecasting model included in the meteorological factors is of high precision and fast speed.

\section{Short-term power load forecasting}

\section{1 grey prediction model}

The main feature of grey prediction is that the model uses the generated data sequence, and its core system is the grey model, that is, the original data is accumulated to generate approximate exponential law, and then the modeling method. The main steps are as follows:

(1) Inspection and processing of data

First of all, in order to ensure the feasibility of the modeling method, need to do the inspection processing necessary for the known data, provided reference data for 
$\mathrm{x}^{(0)}=\left(\mathrm{x}^{(0)}(1), \mathrm{x}^{(0)}(2), \cdots, \mathrm{x}^{(0)}(\mathrm{n})\right)$, the class ratio of series calculation.

$$
\lambda(\mathrm{k})=\frac{\mathrm{x}^{(0)}(\mathrm{k}-1)}{\mathrm{x}^{(0)}(\mathrm{k})}, \mathrm{k}=2, \cdots, \mathrm{n}
$$

If all the class ratio falls on accommodation within the coverage of $\Theta$.

$$
\Theta=\left(\mathrm{e}^{\frac{-2}{\mathrm{n}+1}}, \mathrm{e}^{\frac{2}{\mathrm{n}+2}}\right)
$$

Then $\mathrm{x}^{(0)}$ can be used as data of grey prediction. Otherwise, we need to do the necessary transformation processing of $\mathrm{x}^{(0)}$

Then make a series

$$
\mathrm{y}^{(0)}(\mathrm{k})=\mathrm{x}^{(0)}(\mathrm{k})+\mathrm{ck}=1, \cdots, \mathrm{n}
$$

$$
\lambda_{\mathrm{y}}(\mathrm{k})=\frac{\mathrm{y}^{(0)}(\mathrm{k}-1)}{\mathrm{y}^{(0)}(\mathrm{k})} \in \Theta, \mathrm{k}=2, \cdots, \mathrm{n}
$$

(2) Model building;

We establish the GM $(1,1)$ model by grey forecasting method, and obtain the prediction value

$$
\hat{\mathrm{x}}^{(1)}(\mathrm{k}+1)=\left(\mathrm{x}^{(0)}(1)-\frac{\mathrm{b}}{\mathrm{a}}\right) \mathrm{e}^{-\mathrm{ak}}+\frac{\mathrm{b}}{\mathrm{a}}, \mathrm{k}=0, \cdots, \mathrm{n}-1, \cdots
$$

and

$$
\hat{\mathrm{x}}^{(0)}(\mathrm{k}+1)=\hat{\mathrm{x}}^{(1)}(\mathrm{k}+1)-\hat{\mathrm{x}}^{(1)}(\mathrm{k}), \mathrm{k}=1, \cdots, \mathrm{n}-1, \cdots,
$$

(3) Model accuracy test

The residual test is carried out, and the residual value is epsilon $\varepsilon(\mathrm{k})$

$$
\varepsilon(\mathrm{k})=\mathrm{x}^{(0)}(\mathrm{k})-\hat{\mathrm{x}}^{(1)}(\mathrm{k}), \mathrm{k}=1, \cdots, \mathrm{n}
$$

Here, $\mathrm{x}^{(0)}(1)=\hat{\mathrm{x}}^{(0)}(1)$, if $\varepsilon(\mathrm{k})<0.2$, it can be considered to reach general requirements; if $\varepsilon(\mathrm{k})<0.1$, it can be considered to achieve higher requirements.

\subsection{Power load forecasting model considering meteorological factors}

\subsubsection{Selection of meteorological factors based on principal component analysis}

Let $X_{1}, \cdots, X_{m}$ express the random variables that use $x_{1}, \cdots, x_{m}$ as the sample observations, if you can find $c_{1}, \cdots, c_{p}$, and

$$
\begin{gathered}
\operatorname{Var}=\left(c_{1} X_{1}+c_{2} X_{2}+\cdots+c_{p} X_{p}\right) \\
c_{1}^{2}+c_{2}^{2}+\cdots+c_{p}^{2}=1
\end{gathered}
$$

Let $Z_{i}$ denote the I principal components, $\mathrm{i}=1,2, \cdots, \mathrm{p}$, then we can set up

$$
\left\{\begin{array}{c}
Z_{1}=c_{11} X_{1}+c_{12} X_{2}+\cdots+c_{1 P} X_{P} \\
Z_{2}=c_{21} X_{1}+c_{22} X_{2}+\cdots+c_{2 P} X_{P} \\
\vdots \\
Z_{P}=c_{P 1} X_{1}+c_{P 2} X_{2}+\cdots+c_{P P} X_{P}
\end{array}\right.
$$

Among them, for each I, there are

$$
c_{i 1}^{2}+c_{i 2}^{2}+\cdots+c_{i p}^{2}=1
$$

And $\left[c_{11}, c_{12}, \cdots, c_{1 p}\right]$ has reached the maximum value of $\operatorname{Var}\left(Z_{1}\right)$, then we can achieve all the principal components. 


\subsubsection{Regression analysis model}

The model of multiple linear regression analysis is

$$
\left\{\begin{array}{c}
y=\beta_{0}+\beta_{1} x_{1}+\cdots+\beta_{m} x_{m}+\varepsilon \\
\varepsilon \sim N\left(0, \sigma^{2}\right)
\end{array}\right.
$$

Where, $\beta_{0}, \beta_{1}, \cdots, \beta_{\mathrm{m}}, \sigma^{2}$ is the unknown parameters , and $\beta_{0}, \beta_{1}, \cdots, \beta_{\mathrm{m}}$ is called the regression coefficient. Now we achieve the independent observation data

$$
\left(y_{i}, x_{i 1}, \cdots, x_{i m}\right), \mathrm{i}=1,2, \cdots, \mathrm{n}, \mathrm{n}>\mathrm{m}
$$

And

$$
\left\{\begin{array}{c}
y_{i}=\beta_{0}+\beta_{1} x_{i 1}+\cdots+\beta_{m} x_{i m}+\varepsilon_{i} \\
\varepsilon_{i} \sim N\left(0, \sigma^{2}\right), \quad i=1,2, \cdots, n
\end{array}\right.
$$

Remember

$$
\begin{gathered}
\boldsymbol{X}=\left[\begin{array}{cccc}
1 & x_{11} & \cdots & x_{1 m} \\
\vdots & \vdots & \cdots & \vdots \\
1 & x_{n 1} & \cdots & x_{n m}
\end{array}\right], \quad \boldsymbol{Y}=\left[\begin{array}{c}
y_{1} \\
\vdots \\
y_{n}
\end{array}\right] \\
\varepsilon=\left[\varepsilon_{1} \cdots \varepsilon_{\mathrm{n}}\right]^{\mathrm{T}}, \quad \beta=\left[\beta_{0} \cdots \beta_{\mathrm{m}}\right]^{\mathrm{T}}
\end{gathered}
$$

And

$$
\left\{\begin{array}{c}
Y=X \beta+\varepsilon \\
\varepsilon \sim N\left(0, \sigma^{2} E_{n}\right)
\end{array}\right.
$$

Among them, $\mathrm{E}_{\mathrm{n}}$ is the $\mathrm{N}$ order unit matrix.

\section{Example analysis}

\subsection{The original data}

We use the power load data in X area from January 1, 2016 to January 10 to forecast, in order to obtain the power load data from January 11, 2016 to January17. Table 1 shows the original data.

Table 1 The original data

\begin{tabular}{ccccccc}
\hline Date & $\begin{array}{c}\text { Daily } \\
\text { average } \\
\text { load }\end{array}$ & $\begin{array}{c}\text { Daily } \\
\text { maximum } \\
\text { temperature }\left({ }^{\circ} \mathbf{C}\right)\end{array}$ & $\begin{array}{c}\text { Minimum } \\
\text { temperature } \\
\text { per day }\left({ }^{\circ} \mathbf{C}\right)\end{array}$ & $\begin{array}{c}\text { Daily average } \\
\text { temperature }\left({ }^{\circ} \mathbf{C}\right)\end{array}$ & $\begin{array}{c}\text { Daily } \\
\text { relative } \\
\text { humidity }\end{array}$ & $\begin{array}{c}\text { daily } \\
\text { rainfall } \\
(\mathrm{mm})\end{array}$ \\
\hline 2016.1 .1 & 5165.7760 & 20.3 & 10.2 & 15 & 55 & 0 \\
2016.1 .2 & 4353.6090 & 23.9 & 14.4 & 18.9 & 64 & 0 \\
2016.1 .3 & 2945.6045 & 20.8 & 14.7 & 17.9 & 47 & 0 \\
2016.1 .4 & 4425.8767 & 20.1 & 10.8 & 15.3 & 38 & 0 \\
2016.1 .5 & 4875.9109 & 21.3 & 11.5 & 15.8 & 59 & 0 \\
2016.1 .6 & 4896.3587 & 22.9 & 15.3 & 18.2 & 67 & 0 \\
2016.1 .7 & 5387.5876 & 19.7 & 14.6 & 17.5 & 83 & 0 \\
2016.1 .8 & 5542.0525 & 15.3 & 11.6 & 13.7 & 59 & 0.7 \\
2016.1 .9 & 5558.7564 & 17.4 & 11.6 & 13.9 & 60 & 0 \\
2016.1 .10 & 5557.4157 & 21.6 & 12.5 & 15.8 & 67 & 0 \\
\hline
\end{tabular}

\subsection{Short term power load forecasting based on Grey Model}

(1) Result of grey prediction

According to the grey model, we can obtain the power load prediction values of the area from January 11, 2016 to 17 by using MATLAB. Table 2 shows the result. 
Table 2 The result of grey prediction

\begin{tabular}{cc}
\hline Date & Daily average load \\
\hline 2016.1 .11 & 5165.77 \\
2016.1 .12 & 4173.00 \\
2016.1 .13 & 4395.11 \\
2016.1 .14 & 4629.03 \\
2016.1 .15 & 4875.41 \\
2016.1 .16 & 5134.90 \\
2016.1 .17 & 5408.20 \\
\hline
\end{tabular}

(2) Correlation test

Through the correlation test, the correlation of result is 0.7334 . According to the test standard relational grade, the prediction accuracy meets the requirements.

\subsection{Short-term power load forecasting considering meteorological factors}

(1) Preliminary selection of meteorological factors

A large number of studies showed that the temperature, humidity, wind and other meteorological factors and short-term load changes are particularly important. Table 3 shows the preliminary selection of meteorological factors.

Table 3 The preliminary selection of meteorological factors.

\begin{tabular}{clc}
\hline $\begin{array}{c}\text { Index } \\
\text { source }\end{array}$ & \multicolumn{1}{c}{ Grid load change law } & $\begin{array}{c}\text { Modern power system } \\
\text { characteristics }\end{array}$ \\
\hline Index name & $\begin{array}{l}\text { Daily maximum temperature, Daily minimum } \\
\text { temperature, Daily average temperature }\end{array}$ & $\begin{array}{c}\text { Daily relative humidity } \\
\text { Daily rainfall }\end{array}$ \\
\hline
\end{tabular}

We select the five typical meteorological factors, and investigate the relation of daily maximum load, minimum load, daily peak valley difference in $\mathrm{X}$ with the five meteorological factors. We do the implementation of standardized processing to get the number of data sample correlation coefficient matrix.

Five characteristics value of the correlation coefficient matrix are $0.6480,0.0035,0.0382$, $0.1146,0.1957$. The second characteristic value close to 0 , the other eigenvalues and the proportion reached 0.9965. So we spent the second components. Through principal component analysis, we prefer four meteorological factors, which are recorded as $\hat{x}_{1}, \hat{x}_{2}, \hat{x}_{3}, \hat{x}_{4}$.

(2) Load forecasting results

On the basis of regression analysis, we obtain the principal component regression equation.

$$
\begin{aligned}
& \hat{y}_{1}=3748.0118+39.3411 \hat{x}_{1}-171.7102 \hat{x}_{2}+356.9330 \hat{x}_{3}-13.3905 \hat{x}_{4} \\
& \hat{y}_{2}=2416.7031+19.0333 \hat{x}_{1}+29.6342 \hat{x}_{2}+95.7799 \hat{x}_{3}-14.6848 \hat{x}_{4} \\
& \hat{y}_{3}=3254.1055+33.9603 \hat{x}_{1}-80.0209 \hat{x}_{2}+229.0182 \hat{x}_{3}-14.7421 \hat{x}_{4}
\end{aligned}
$$

We use principal component regression equation to predict the load. Table 4 shows the result.

Table 4 The result

\begin{tabular}{cc}
\hline Date & Daily average load \\
\hline 2016.1 .11 & 5165.76 \\
2016.1 .12 & 4183.21 \\
2016.1 .13 & 4393.21 \\
2016.1 .14 & 4633.57 \\
2016.1 .15 & 4866.61 \\
2016.1 .16 & 5135.89 \\
2016.1 .17 & 5407.11 \\
\hline
\end{tabular}




\subsection{Comparative analysis of two forecasting model}

We compare the load forecasting results of these two models with the actual load. As shown in the figure 1. As can be seen from the diagram, the predicted value curve of short-term power load considering meteorological factors is closer to the real data curve. Therefore, it can be considered that the accuracy of load forecasting can be improved after considering the meteorological factors.

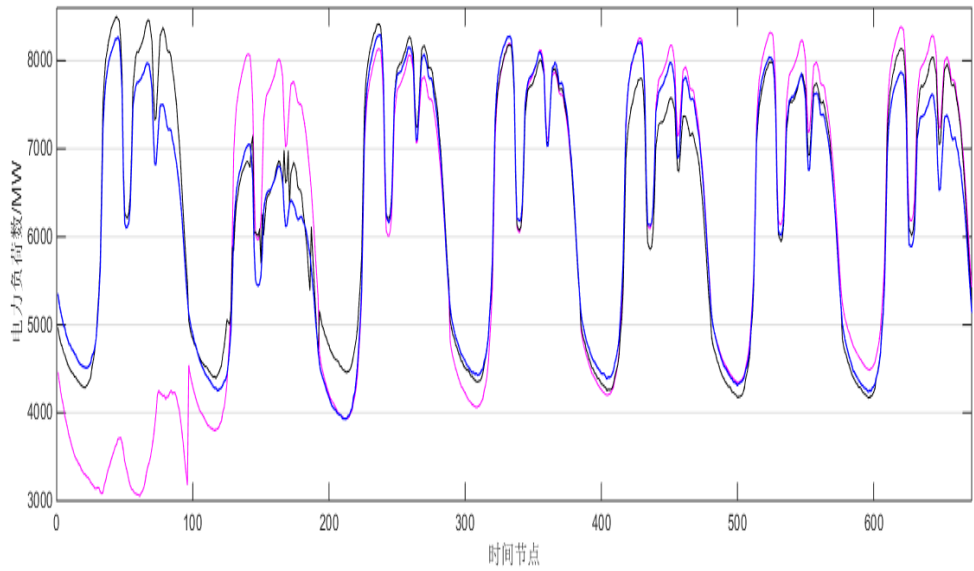

Figure1 Comparison the load forecasting results

\section{Conclusion}

(1) We establish a short-term load forecasting model based on grey prediction. Using the grey model for short-term load forecasting, it can solve the lack of history data, the sequence of integrity and reliability low while does not require a lot of data.

(2) We establish a principal component regression analysis model considering meteorological factors. Principal component regression analysis makes the prediction result more accurate.

(3) We analyze the fitting degree between the two forecasting models and the actual load curve. The results show that the model considering meteorological factors is more accurate.

\section{References}

[1] Lijun Sun, Dong Liu. Study on combined forecasting of medium and long term power load based on Grey Theory and regression analysis [J]. Journal of North China Electric Power University, 2011, S2:132-134.

[2] Xiaojuan Liu. Power system load forecasting model based on intelligent method and its application [D]. Donghua University, 2014.

[3] Shoukui Si, Xijing Sun. Modeling and application of mathematics. National Defense Industry Press, 2015.

[4] Dengyuan Zhu, Xiaofeng Chang. Matlab realization of grey prediction GM (1,1) model [J]. Journal of Henan University Of Urban Construction, 2013,03:40-46.

[5] Peng Peng, Jiahong Peng. Study on power load forecasting based on multiple linear regression model [J]. China safety production science and technology, 2011,09:158-161.

[6] Yahong Chen, Li Ma, Gang Mu, Xianping Zhang, Guoying Fan. Comparison of two kinds of short-term load forecasting accuracy assessment [J]. automation of electric power systems, 2010,17:73-77. 